\title{
Congratulations to V.P. Vavilov
}

DOI: $10.1134 / \mathrm{S} 1061830909080129$

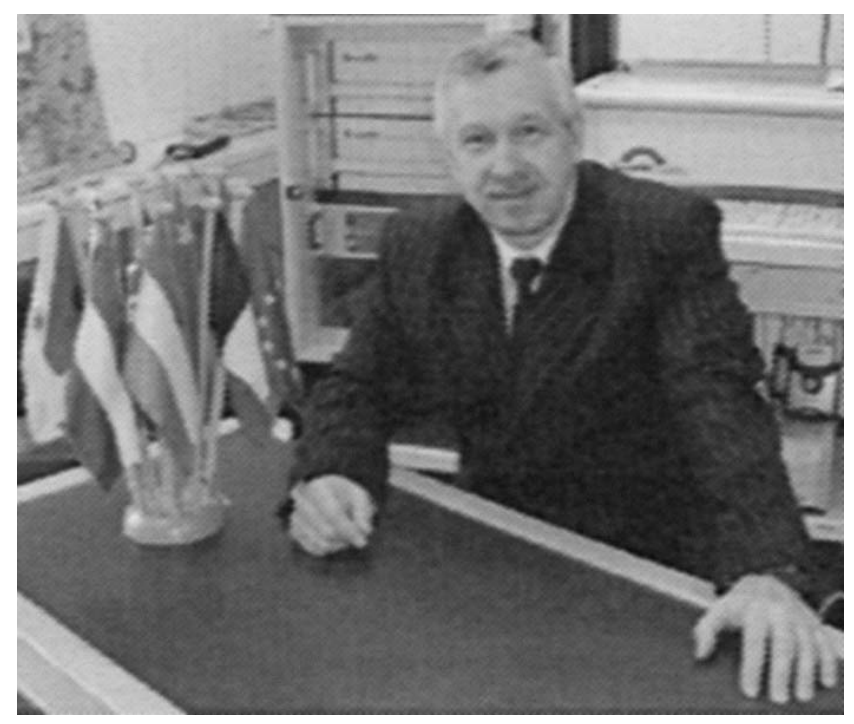

Vladimir Platonovich Vavilov, a member of the editorial board of our journal, celebrates his 60th birthday. Professor Vavilov is a doctor of engineering, an honored scientist of the Russian Federation, an honorable employee of higher and professional education, a laureate of a Prize of the Government of the Russian Federation in 2004, a man of the year of the city of Tomsk in 2006, a vice-president of the Russian Society of Nondestructive Testing and Technical Diagnostics (RSNDTTD), an academician of the International Academy of Nondestructive Testing, an academician of the International Academy of Infrared Thermography, a representative of the Commonwealth of Independent States in the European Working Group "Euroterm," a member of the International Committee ISO/TC 135/SC, an expert of MAGATE in the field of thermal testing, an instructor of the International Certification Center in the field of IR thermography, an expert of Russian Technical Regulation on certification of foreign companies, and the chairman of the conference "Thermosens" (United States). Vladimir Platonovich is the author of more than 200 scientific publications. He was awarded a Medal of Academician S.P. Korolev by the Federation of Cosmonautics.

The editorial board of our journal and the scientific community cordially congratulate him and wish him good health and further achievements in his multifarious investigations. 